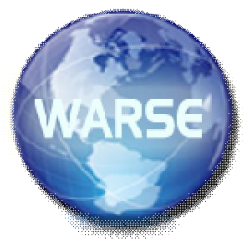

\author{
International Journal of Information Systems and Computer Sciences \\ Available Online at http://warse.org/IJISCS/static/pdf/file/ijiscs21822019.pdf \\ https://doi.org/10.30534/ijiscs/2019/21822019
}

\title{
ADVANCED SURVEILLANCE AND STRATEGIC WARNING SYSTEM FOR THE SAFETY OF MINEWORKERS
}

\author{
Karthika Rajeev ${ }^{1}$, Kripa Sara Thomas 2 , Sheba Jiju George 3 \\ ${ }^{1}$ Student, Department of Computer Science, Mangalam College of Engineering, India, karthikarajeevm@gmail.com \\ ${ }^{2}$ Student, Department of Computer Science, Mangalam College of Engineering, India, kripasarathomas26@ gmail.com \\ 3 Assistant Professor, Department of Computer Science, Mangalam College of Engineering, India, sheba.jiju@mangalam.in
}

\begin{abstract}
The mining enterprise is a major industry which plays a significant role in the economic system of many nations. But most of the mining industries face major questions of safety issues like huge explosions caused by the accidental accumulation of poisonous gases like $\mathrm{CH} 4, \mathrm{C} 2 \mathrm{H} 2$, and $\mathrm{CO}$ which leads to the massive death of many people in the mining industry. The existing monitoring and pre-warning system use mine communication cable which are hazardous and more prolonging of maintenance cost for passing the important data required to prevent the occurrences of huge casualties. To solve these issues, in this research paper we introduce a new clustering data aggregation strategy and we use the Euclidean distance calculation method in hazardous situations to send the necessary data collected from the sensors via WSN network.
\end{abstract}

Key words: Big Data, Cluster heads, CPWI, Euclidean Distance.

\section{INTRODUCTION}

In India, the essential manufacturing of electricity is through energy resources. Fast boom desires and upliftment of humans out of poverty, India walks a decent rope between fueling its wishes with inexpensive however harmful assets versus becoming a clean energy leader. India is a rustic of over 1 billion human beings living, around 18\% of the vector population. $60 \%$ of Indians live in rural areas and at the least 240 million don't have any access to electricity. Energy consumption has now grown to be doubled due to which intake of non- renewable energy sources has also expanded. So mining is the major source for extracting energy resources. So, it is necessary to provide more attention to the safety of the labors in the mines we propose to use WSN, Big data, IoT, and AI technologies to build "digital mine"[1]. The accumulation of toxic gases like $\mathrm{CH} 4, \mathrm{C} 2 \mathrm{H} 2$, and $\mathrm{CO}$, fuelair explosions, the collapse of mine stopes, size of the data or the scale and growth of the data set [3]. And the characteristics of big data are the six V's(as shown in fig 1) i.e. Velocity, Value, Volume, Variability, Veracity and Variety [3]. We use this big data to implement an effective surveillance system and an improved strategic warning system.

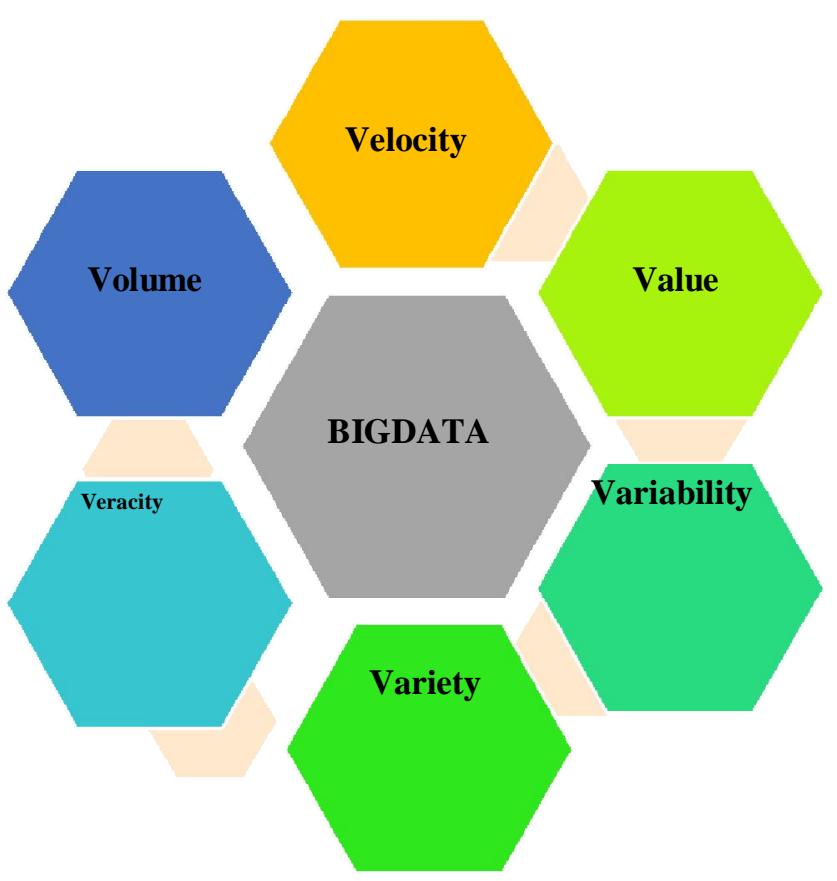

Figure 1: Six V's of Big data 
Earlier instead of technologies like AI, Big data and IoT, traditional mine communication cables were used which were highly vulnerable to damage and may lead to the entire system breakdown in accidents involving roof falls, fire and mine collapse [4]. So, the conventional mine communication cable was replaced by wireless sensor networks. With the introduction of sensor networks in the mining industry, there arises a problem on how to increase the lifespan of the sensor nodes.

Since the surveillance system produces a huge amount of data every day, if we are able to use this data efficiently, we can know the accident in advance and take appropriate measurements to prevent the happening of the accidents [1]. Reference [5] proposed if we want to replace the cable and we want to use big data in the mining industry with WSN, we really have to focus on the efficient utilization of energy. This paper mainly focuses on how to use big data, IoT, AI, clustering data aggregation strategy and the Euclidean distance calculation in the surveillance and strategic warning system efficiently.

\section{EXISTING SYSTEM}

The exploding world of Big data possesses, more than ever, two challenge classes: engineering-efficiently, managing data at unimaginable scale;

and semantics-finding and meaningfully combining information that is relevant to your concern [6]. The major struggle faced by the mining industry is how to analyze and retrieve too many information like maintenance of the mining equipment, cartographical data, environmental data and so on quickly to obtain the real time results. The existing WSN network consists of sensor nodes and sink nodes. The sink nodes connect to each other using the mine communication cable(as shown in figure 3) and are placed near the junction of the main pathway[1]. The sensor nodes collect millions of big data. This information collected is used to prevent the occurrences of hazardous situations. But the use of mine communication cable is really timeconsuming and causes great delay in extracting the important data necessary to prevent accidental situations like explosions etc.

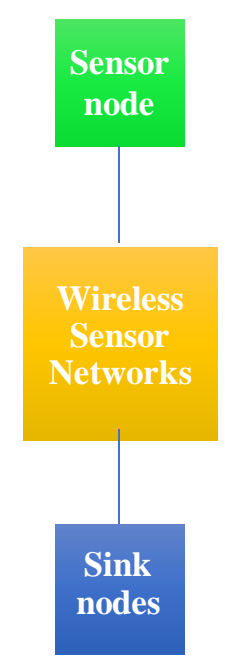

Figure 2: Wireless Sensor Networks

With the replacement of mine communication cable with WSN, we need to extend the battery life of sensors to their maximum to efficiently limit the maintenance cost. Most of the mines mainly focus on implementing the surveillance and strategic warning system in the underground. The Native Administration of Work Safety requires knowing the realtime production state of each mine(as shown in figure 4), so all of the observance information is sent to the information center of the Native Administration of Labour Safety [1]. The major disadvantage in this structure is that if any disruptions occur in this mines then no data will reach in the strategic warning system and hence the system fails to transmit the data.

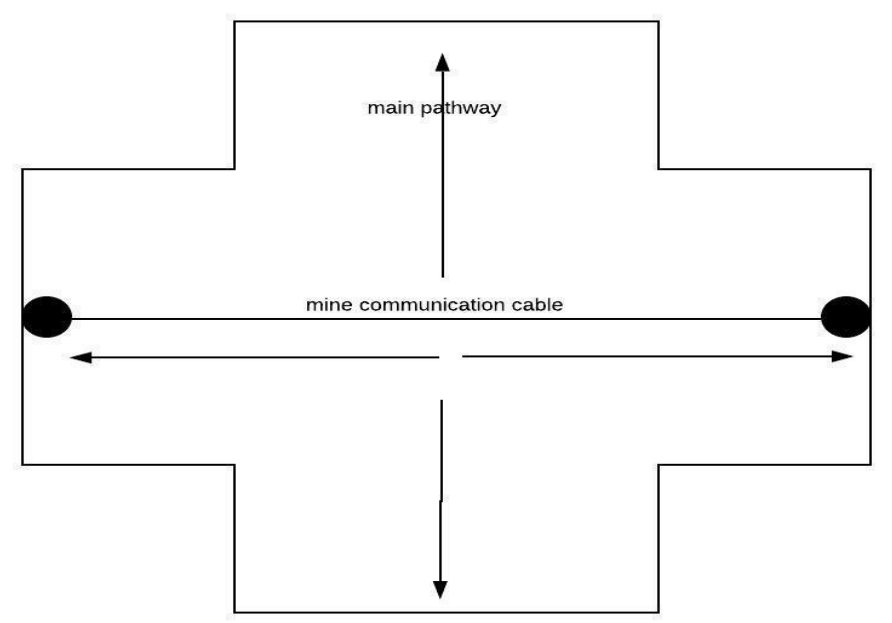

Figure 3: pathway of the mine communication cable. 


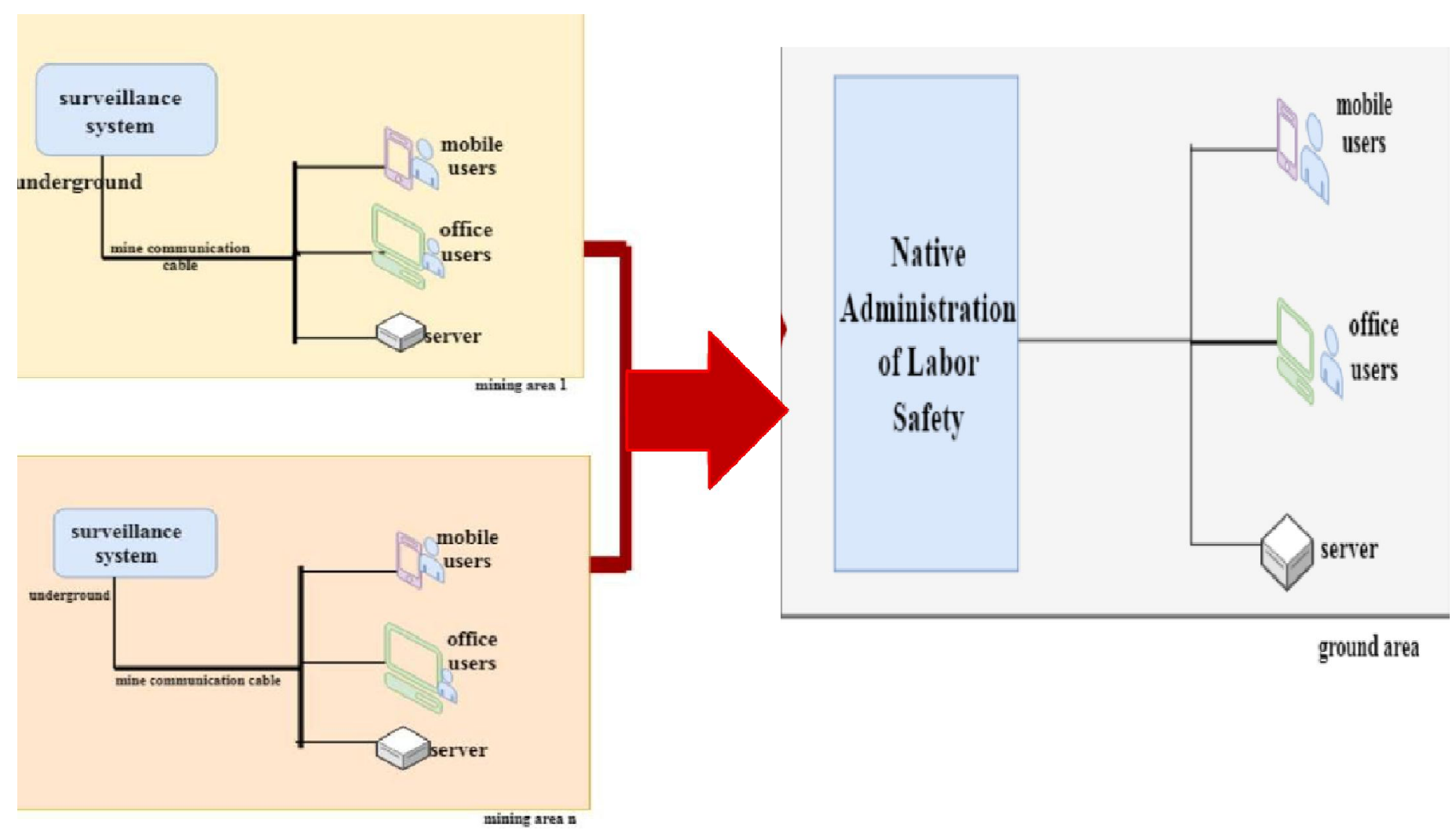

Figure 4: Structure of the existing system.

\section{DESIGN OF THE PROPOSED SYSTEM}

The design of the surveillance and strategic warning system mainly focuses on the Big data. The traditional mine communication cable is replaced by Wireless Sensor Networks. Reference [7] propose to manage the sensors in an efficient way each requires a unique ID and after sensing the data we need to characterize it on the basis of specified context parameters.

Our paper mainly focuses on the optimal distance calculation by Euclidean method to transmit the critical data in hazardous situations. In this step, the sensors are ranked based on the proximity-based sensed critical data. We are adopting a weighted Euclidean distance based indexing technique, Comparative Priority based Weighted Index (CPWI).

n

(CPWI) $2=\sum[\mathrm{Wi}(\mathrm{Ui4}-\mathrm{Si} 4) 2] \mathrm{i}=1$
First, each sensor is plotted in multi-dimensional space where each sensor is collecting the data related to the mine temperature and heat. Then we can plot a critical sensor in the multidimensional space by comparing the threshold value for both the criteria. By default, our system will automatically plot an ideal sensor with a threshold met. Next taking the nearest sensor to the critical one, if it is reaching that threshold. Based on the positions of the sliders weights are calculated in a comparative fashion. The algorithm describes the indexing of cluster head communication process. It calculates the cluster heads to communicate with the network regarding the critical data that was read and need to be sent.

\section{ALGORITHM}

The main disadvantage of the existing system is that the surveillance and strategic warning system only collects data from an entire mining area. Any accidents in that particular zone will block the data of the entire mining area in reaching the Native Administration for Labour Safety [1].

The main advantage of creating different cluster heads within the same mining area gives us the critical value of the entire mine during the time of emergency situations. 


\subsection{STEPS FOR ALGORITHM}

A) Create each cluster in a radius of $1 \mathrm{~km}$.

B) Determine and place a cluster head which will act as a server for the other nodes.

C) Once a sensor detects a critical value then calculate the Euclidean distance to the nearest heads.

D) Transmit the data via more than one cluster.

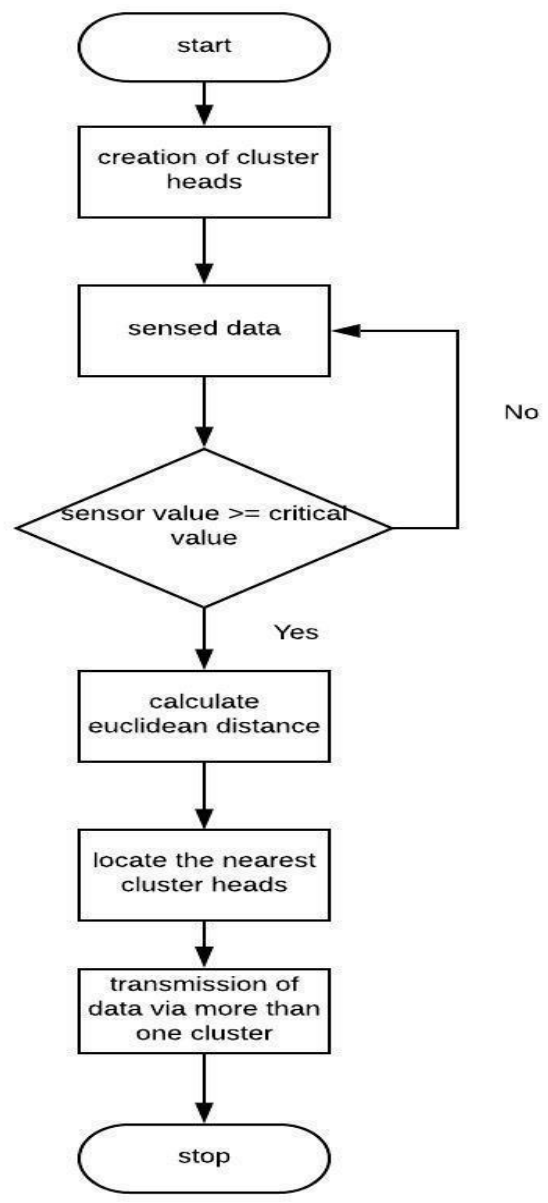

Figure 5: Flowchart for the proposed system

\section{CONCLUSION}

In this paper, we focused on the effective way of surveillance and strategic method for the huge collection of data based on big data. Through the Clustering of head technology, we can collect a wide amount of data even in the midst of an emergency situation without any hype. We also calculate the nearest cluster heads in an emergency situation with the help of Euclidean distance calculation formula known as Comparative Priority Based Weighted Index. Thus transmitting critical data via different clusters without any hindrance which is more effective and proficient than the existing method for transmission of data.

\section{REFERENCES}

1.Xu Xia, Zhigang Chen and Wei Wei, Research on Monitoring and Prewarning System of Accident in the Coal Mine Based on Big Data, Scientific Programming, vol 2018. https://doi.org/10.1155/2018/9308742

2."Mining Accidents" https://en.wikipedia.org/wiki/Mining_accident. 3.Jonatan Adam Fekete. Big Data in Mining operations, Master's Thesis, MSc Business Administration and Information Systems. Copenhagen Business School, Denmark, 20165

4.Ranjan A. and Sahu, H.B. 2014. "Communication Challenges in Underground Mines" Search Research, Vol. V No. (2) pp. 23-29, 2014 https://doi.org/10.1097/01.BACK.0000443962.90786.e5

5.E. Sun, X. Zhang, and Z. Li, "The internet of things (IOT) and cloud computing (CC) based tailings dam monitoring and pre-alarm system in mines," Safety Science, vol. 50, no. 4, pp. 811-815, 2012. https://doi.org/10.1016/j.ssci.2011.08.028

6.C.Bizer, P. Boncz, M.L. Brodie, and O. Erling, "The meaningful use of big data: four perspectives-four challenges," ACM SIGMOD Record, vol. 40, no. 4, pp. 56, 2011.

https://doi.org/10.1145/2094114.2094129

7.K. R. Ramesh Babu, Sheba Jiju George, Philip Samuel "Optimal Sensor Selection from Sensor Tool in IoT Environment", in 2nd International Conference on Applied and Theoretical Computing and Communication Technology, India, 2016. 